\title{
Arte da felicidade, melancolia da arte
}

\author{
Jefferson W.Kielwagen ${ }^{1}$
}

\section{Palavras-Chaves: Artes, mercado, cultura}

Resumo: O presente ensaio sugere algumas conexões entre kitsch e melancolia: pontos de partida para uma leitura diferente dos dilemas e ironias que confrontam a arte na contemporaneidade. Uma investigação mais detalhada dessa relação revela alguns aspectos inusitados da sensibilidade contemporânea em relação à arte.

Historicamente, o kitsch parece ser constituído por uma relação de duas vias entre felicidade e melancolia - a arte da felicidade como contraponto à melancolia da arte. No centro dessa relação estaria a subjugação da cultura à avassaladora lógica de mercado que se instaura com o capitalismo, regendo a partir de então todos os aspectos da vida. Como já foi colocado por Greenberg e Adorno, há uma correspondência entre a ascensão do kitsch e a reinvenção dos gêneros artísticos, diante de seu esgotamento - fato pouco explorado no campo teórico da arte, que normalmente se propõe a ler o kitsch em seus aspectos puramente formais. As relações entre aquilo que chamamos kitsch e a percepção de uma melancolia generalizada, que permeia a maior parte do ocidente industrializado, servem de pontos de partida para uma leitura diferenciada dos dilemas e ironias que a confrontam na contemporaneidade.

Abraham Moles definiu o kitsch como "a arte da felicidade" justamente por representar os valores da sociedade burguesa em ascensão durante a revolução industrial. Daí o princípio de conforto - um dos cinco princípios kitsch delineados por Walter Killy: os novos materiais e meios de produção, tornados disponíveis pelo avanço tecnológico, foram tomados como símbolos da posição social privilegiada da classe dominante como forma de auto-afirmação e ostentação de prosperidade - retratando necessariamente uma imagem de fartura e bem-estar. Theodor Adorno, Hermann Broch, e Clement Greenberg 1 Aluno do Curso de Mestrado em Artes Visuais CEART - UDESC

DAPesquisa, Florianópolis, v.2, n.4, p. 182-186, 2007. 
são unânimes em suas definições de kitsch como oposto à vanguarda e, sobretudo, como um tipo de falsa consciência - termo marxista significando uma sensibilidade específica do capitalismo, onde o indivíduo é desviado de seus próprios desejos e vontades.

A sujeição da cultura à lógica de mercado, bem como a posição ambígua do artista diante do sistema de produção capitalista, vêm rendendo discussões desde o final do século IX. Em 1891, Oscar Wilde publicou um ensaio intitulado “A Alma do Homem sob o Socialismo", que antecipa e resume parte dos dilemas da arte no século que se seguiria. Ao refletir sobre o espaço da arte em um mundo industrializado, afirma que "a sociedade, por meio da organização da maquinaria, fornecerá o que é útil; o que é belo será criado pelo indivíduo". Implícitas nessa afirmação estão três idéias bastante discutidas pelos artistas de sua época: primeiro, a relação entre arte e beleza - que seria subvertida poucas décadas depois, na medida em que os produtos industrializados tornavam-se mais belos do que objetos artísticos; segundo, a oposição entre forma e função - também superada pelas vanguardas do século XX; e por fim, a crença na continuidade de um espaço próprio para a arte na sociedade moderna, um espaço intocado pelo mercado, pela produção em massa e pelo consumo rápido. Essa terceira idéia, diferente das anteriores, persiste até a contemporaneidade - e empurra os artistas para o campo expandido, para a desmaterialização e para a melancolia de se ver à deriva.

\section{O bicho da seda em meio à produção em massa}

É consenso que a transformação do objeto artístico em produto consumível - seja pelo mercado de decoração, pelo mercado de entretenimento ou pela indústria cultural põe em questão o espaço da arte na contemporaneidade. Reprodução em série, comercialização, massificação e homogeneização são temas recorrentes, que atravessam vários movimentos culturais e dividem os artistas entre os que dançam conforme a música e os que nadam contra a maré. Os primeiros - artistas pop e pós-pop, artesãos e designers

- se apropriam do kitsch (ou são apropriados por ele). Já os segundos - os românticos, as vanguardas, o situacionismo e seus derivados - o combatem. A arte contemporânea, de uma maneira geral, combate o kitsch quando procura transcender o papel a ela outorgado pelo mercado, criando ou descobrindo novas funções, tentando inserir-se em outros espaços e, sobretudo, negando seu papel na indústria do entretenimento.

DAPesquisa, Florianópolis, v.2, n.4, p. 182-186, 2007. 
Idealismos à parte, diante da dicotomia entre trabalho produtivo e não-produtivo já apontada por Marx a propósito do Paraíso Perdido - o artista fica em apuros. No Brasil, o crítico brasileiro Mário Pedrosa registrou todo o seu pessimismo em relação ao espaço da arte na sociedade moderna, comparando o artista a um bicho da seda que produz muito lentamente em meio aos teares da civilização. O dilema do "bicho da seda em meio à produção em massa" foi abordado durante a Exposição Nacional de Arte Concreta - em 1956 no MAM-SP, e 1957 no Ministério da Educação e da Cultura no Rio de Janeiro - pelos grupos concretos Ruptura e Frente, ambos vindo de uma mesma raiz construtivista que acreditava no progresso industrial e no reposicionamento da arte, que possuiria então uma função direta na organização da vida moderna e não mais uma atitude contemplativa e mistificadora. Mas apesar do otimismo de alguns, em 1967 Pedrosa ainda pergunta:

“... onde estão as condições sociais e culturais que permitam a esses bichos continuar a produzir incessantemente a sua seda e a usar de seu dom natural em toda a liberdade? Como conservá-la em sua autenticidade original e como distribuí-la, sem alterá-la na sua existência intrínseca, ou como doá-la, trocá-la numa sociedade com sedas sintéticas em abundância e entregue ás mobilizações em massa e aos divertimentos em massa?" Pergunta também se a busca por uma arte "pura" não se resolveria na sujeição desta à racionalidade da máquina, ao desenho industrial "mais próximo do trabalho de engenharia do que do de artistas" e conclui, enfim, que a pósmodernidade é a cultura da publicidade e do detrito, onde as técnicas de comunicação avançam sobre a imaginação dos artistas num desenvolvimento cada vez mais autônomo até que, por fim, arte e mercadoria estejam no mesmo sistema de objetos.

Ainda em “A Alma do Homem sob o Socialismo", Oscar Wilde sugeriu que “... sempre que uma sociedade, ou um poderoso segmento da sociedade, ou um governo de qualquer espécie, tenta impor ao artista o que ele deve fazer, a Arte desaparece por completo, torna-se estereotipada, ou degenera em uma forma inferior e desprezível de artesanato". Pedrosa também acreditava em uma arte de natureza espiritual, como Wilde, para quem as necessidades da arte são as do próprio espírito. Ao elogiar os estábiles e móbiles de Calder, ressalta uma oposição ao mundo dominado pelo intelecto, reagindo ao desencantamento do mundo que os teóricos da modernização ocidental costumam assinalar. Diante da ameaça da diluição da arte na mercadoria, via em iniciativas extremas - como o Neoconcretismo e os Happenings - formas de preservar sua autonomia. Por fim, notando o excesso de complacência com o espetáculo que reina na pós-modernidade, aproxima-se do idealismo DAPesquisa, Florianópolis, v.2, n.4, p. 182-186, 2007. 
de Wilde atacando duramente a arte pop: "Não são artistas porque são técnicos da produção de massa. São especialistas que trabalham para a atividade decisiva da sociedade americana."

\section{Dessacralização como fonte de melancolia}

Por dessacralização da arte, entendo todo tipo de desmistificação da obra de arte e da figura do artista - que já ocupou, no imaginário popular, lugares intermediários entre os do professor e do sacerdote. A aura religiosa foi a primeira a ser removida. Foi substituída por outras qualidades durante o romantismo - como excentricidade e sensibilidade - e até o modernismo, as vanguardas ainda preservavam parte de sua reputação de gênios visionários. Mas na pós-modernidade mesmo o glamour das vanguardas foi removido; o artista tornou-se uma espécie de operário a serviço da indústria do entretenimento.

Nas palavras de Mário Pedrosa, se durante o modernismo ainda havia algum otimismo em relação ao futuro da arte, ele tinha sido barrado pela "avalanche do mercado". O futuro da arte parecia-lhe cada vez mais incerto: "Até o momento da pop art, os artistas tinham noção de que iam inovando o enredo, a problemática, da arte moderna, inspirados nas artes primitivas (...), hoje a arte é cada vez mais um produto da indústria e portanto do mercado. (...) Não existem mais vanguardas. (...) A arte não irradia mais influência, não desperta mais a atenção. (...) Diante de conflitos tão radicais, terríveis, insolúveis, é natural que a arte passe para um nível secundário." A dessacralização da arte, então, é o desagradável resultado de sua sujeição à lógica de mercado. Naturalmente, educação e sacerdócio também foram "rebaixados" a categorias de prestação de serviços, para a atender às demandas de outros mercados; é como se o capitalismo tivesse o poder de dessacralizar todas as coisas que toca, transformando-as em mercadorias e esvaziando-as de seus significados originais. Operações como banalização, esvaziamento e massificação estão na base das relações entre arte e kitsch, psicologia e auto-ajuda ou religião e esoterismo. Ora, diante de um reposicionamento e re-dimensionamento tão súbitos de seus papéis, parece apenas natural que os herdeiros desses saberes - instituídos ao longo de séculos de história - expressem uma certa melancolia.

DAPesquisa, Florianópolis, v.2, n.4, p. 182-186, 2007. 


\section{kitsch e espetáculo}

A “sociedade do espetáculo", conforme descrita por Guy Debord, tem uma série de características em comum com o kitsch que merecem ser assinaladas. As semelhanças são tantas que me pergunto se o kitsch e o espetáculo não seriam leituras diferentes de um mesmo fenômeno, em contextos ligeiramente diferentes. Por exemplo, quando Debord sugere que a dominação da economia sobre a vida social leva, num primeiro momento, a uma inevitável degradação do ser em ter e, em seguida, a um deslizar generalizado do ter em parecer, ele concorda com os teóricos que viram no avanço do capitalismo os sinais da decadência da arte. Além disso, ao afirmar que o espetáculo "nada mais seria que o excesso do midiático", Debord chega perto de uma das mais pungentes definições para o kitsch cunhadas por Abraham Moles: “o resultado do excesso de meios em face das necessidades".

Outro ponto em comum é a capacidade que tanto o kitsch quanto o espetáculo têm de assimilar os movimentos culturais que lhes são contrários, coptando-os e recrutando-os a seu serviço. Assim, temos a "crítica espetacular do espetáculo", o deslocamento dos movimentos hippie e punk das ruas para as boutiques, reproduções de grandes obras de arte em figurinhas de chiclete e a transformação de figuras políticas e religiosas - como Nossa Senhora Aparecida ou Che Guevara - em ícones pop de uma geração materialista e politicamente analfabeta.

\section{Referências}

ADORNO, Theodor. Indústria Cultural e Sociedade. São Paulo : Paz e Terra, 2002.

ARANTES, Otília Beatriz Fiori. Mário Pedrosa: itinerário crítico. São Paulo: Cosac Naify, 2004.

DEBORD, Guy. A sociedade do espetáculo. Rio de Janeiro: Contraponto, 1997.

GREENBERG, Clement. Arte e Cultura - Ensaios críticos. São Paulo : Ática, 1986.

KIELWAGEN, Jefferson W. Kitsch \& Design Gráfico. Joinville : SE, 2004.

MOLES, Abraham. O Kitsch. São Paulo : Perspectiva, 1991.

WILDE, Oscar. A Alma do Homem sob o Socialismo. Porto Alegre : L\&PM Editores, 2003.

DAPesquisa, Florianópolis, v.2, n.4, p. 182-186, 2007. 